\title{
OPTIMISING ALKALOID YIELD IN CATHARANTHUS ROSEUS
}

\section{LAKSHMI S. R. ARAMBEWELA, J. RANATUNGE, SHANTHA WIJERATNE, PUSHPA FERNANDO AND KAMANI WICKRAMASINGHE \\ Natural Products Section, Ceylon Institute of Scientific and Industrial Research, P.O. Box 787, Colombo 7.}

(Date of receipt $\quad \therefore \quad 16$ October 1992)
(Date of acceptance $\quad: \quad$ 05 April 1993)

\begin{abstract}
Field trials on Catharanthus roseus were carried out to determine the best time to harvest plants for production of alkaloids. Foliar application of plant nutrients containing the major and minor essential elements and plant hormones produced a significant increase in dry matter and alkaloid content in the leaves and roots of the plant. It was observed that the treatment with micro elements together with either cattle manure or NPK gave the highest increases in dry matter and alkaloid content.
\end{abstract}

Key words : Alkaloids, Catharanthus roseus, foliar application, micro elements, optimal yields.

\section{INTRODUCTION}

Many developing countries, including Sri Lanka, grow plants for the production of pharmaceuticals. Catharanthus roseus belongs to family Apocynaceae. There are three formas in $C$. roseus. The most common one, the forma rosea, was selected for our studies. Over seventy five alkaloids have been reported from this plant. ${ }^{1}$ The two alkaloids vincristine and vinblastine, used as anticancer agents, are present in the leaves of $C$. roseus. Ajmalicine present in the roots has anti-fibriliar properties. Studies on optimising alkaloid yields are required since there is a demand for the roots and leaves of $C$. roseus in the international market. Chatterjee and co-workers have observed that foliar spray of iron and magnesium had pronounced effects on the formation of total alkaloids. ${ }^{2}$

The work presented here reports on the establishment of an optimum harvest time for $C$. roseus based on yields of total alkaloids and total dry matter and the effects of fertilizer, foliar application of plant nutrients, manures and stress conditions on the dry matter and alkaloid content.

\section{METHODS AND MATERIALS}

Setting up of the experimental plot: Fresh seeds were broadcast in plot of $4 \mathrm{~m} \times 4.5 \mathrm{~m}$ area of sandy soil at CISIR, and irrigated twice a week. Thinning out of the plants 
were done from two weeks of the broadcasting of seeds to produce a spacing of $30 \mathrm{~cm} \times 30 \mathrm{~cm}$ in between the plants.

Estimation of dry matter yield : Eight plants were randomly selected and uprooted every month for the estimation of dry matter and alkaloids in leaves, stem and roots. Sampling was done from $4^{\text {th }}$ month up to $12^{\text {th }}$ month of maturity. Plant materials were dried in the shade and weights were taken at each maturity stage.

Estimation of total alkaloids yield : Powdered plant material was extracted with dilute acetic acid twice by percolation at room temperature. The resulting solutions .were extracted with chloroform in acidic and basic media. The alkaloids were obtained by evaporating the chloroform extracts. This method was developed in our laboratory.

Estimation of ajmalicine content in the roots : A known quantity of the total alkaloid fraction was separated on silica gel GF tlc plates along with the authentic ajmalicine. The plates were developed in a toluene-ethyl acetate (1:1) solvent system. Ajmalicine content in the sample was estimated by tlc-densitometry at $280 \mathrm{~nm}$ in a Camag automatic scanning densitometer.

Studies on the effect of foliar application of plant nutrients on dry matter and alkaloid content: Field experiments were initiated in August with foliar application of 'Maxi crop' solution (which was a mixture of major and minor elements and plant hormones) diluted 100 times with water. The field trial was conducted with four replicates in randomized complete block design at the CISIR experimental plots. The soil was clay loam with $50 \%$ clay, $18 \%$ silt, $30 \%$ sand. The $\mathrm{pH}$ of the soil was 5.8 .

The seeds for the nursery were obtained from India. After the seedlings were maintained for $\mathbf{4 5}$ days in the nursery they were transplanted in the experimental plots with a spacing of $30 \mathrm{~cm} \times 45 \mathrm{~cm}$, and irrigated once a week during the dry period.

There were two treatments:

1. Addition of nutrient solution

2. No addition

These two treatments were replicated four times to reduce experimental errors. First application of the foliar nutrient was done two months after transplantation using a hand sprayer. Consequently nutrient solution was sprayed once a month up to the $10^{\text {th }}$ month. From the $4^{\text {th }}$ month upto the $12^{\text {th }}$ month after transplantation, 12 plants were harvested randomly from each plot at monthly intervals. After harvesting, each plant was separated into roots, leaves and stems. After drying, the weight of the dry matter was recorded and analysed for alkaloids and ajmalicine content in the roots. ${ }^{3}$ 
Studies to determine the effect of fertilizer, manure and stress condition : The field experiments were initiated in October with treatments consisting of

T1 - No addition (control)

T2 - Cattle manure $(1500 \mathrm{~kg} / \mathrm{h})$

T3 - N.P and K (46 kg, and $30.5 \mathrm{~kg} / \mathrm{h}$ respectively)

T4 - N.P. K and micro elements

T5 - Cattle manure and micro element mixture

T6 - Stress conditions (induced by pruning)

The experiments were carried out in a randomized complete block design with three replicates at the CISIR experimental plots. After the seedlings were maintained for $\mathbf{4 5}$ days in the nursery they were transplanted in the experimental plots with the spacing of $30 \mathrm{~cm} . \times 30 \mathrm{~cm}$. The fertilizer and manure treatments were given at the time of transplanting and the pruning was practised at the $3^{\text {rd }}$ month of maturity. Irrigation was done once a week during the dry period.

Sampling and determination of the dry matter yield : 10 -15 plants were harvested randomly from each plot at the $4^{\text {th }}$ and $10^{\text {th }}$ months of maturity. After harvesting the roots and leaves of each plant were separated. They were then dried in the shade until constant moisture levels were reached. The dry matter yields were recorded before powdering and analysis.

\section{RESULTS AND DISCUSSION}

The changes in the dry matter during the growth of the plant is shown in the Figure 1. This growth curve is useful to study the growth pattern to calculate the expected yield per unit area at different stages of maturity. A rapid increase in the yields was observed after the $5^{\text {th }}$ month. Application of fertilizer after the $4^{\text {th }}$ month may therefore help to enhance the yields.

The $10^{\text {th }}$ month was selected to harvest the plant for best economical yields as sufficient time is then available to prepare the land for re-planting.

Studies on the effects of the foliar application of plant nutrients indicated higher dry matter accumulation in treated plants (Figure 2). Increase in the dry matter content is marked in treated plants upto 10 months of maturity. After the $10^{\text {th }}$ month, dry matter decreased in leaves possibly due to a higher rate of defoliation of leaves. Figure 3 shows the change in alkaloid content in the whole plant with and without treatment. Regression analysis showed that the effect of treatment on the alkaloid content was significant $(p<0.05$ ). The alkaloid content in whole plants was considered due to changes in roots, stems and leaves during transportation. These 


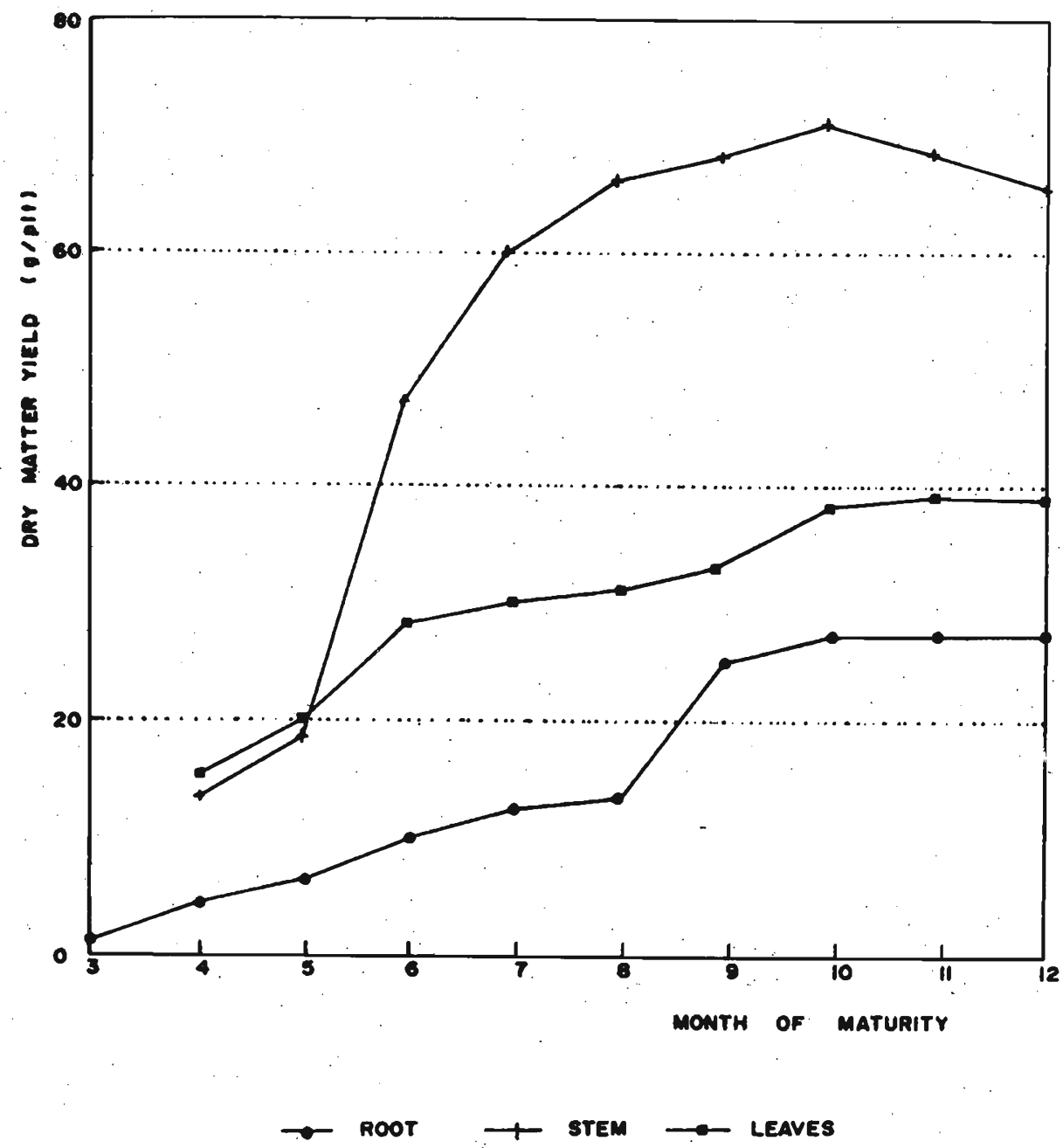

Flgure 1: Changes in dry matter during the growth of $C$. roseus

results are in agreement with those of Chatterjee et al. ${ }^{2}$ who also observed that foliar application of iron and magnesium caused a significant increase in alkaloid content.

It is apparent that the application of the mixture of NPK and micro elements gave the highest yield of roots and alkaloids at maturity (Figures 4 and 5). It is also clear that the application of cattle manure or NPK together with micro elements gave higher yields that when either was used alone. Higher increases in ajmalicine contents too were observed with these two treatments (Figure 6). The cattle manure when 


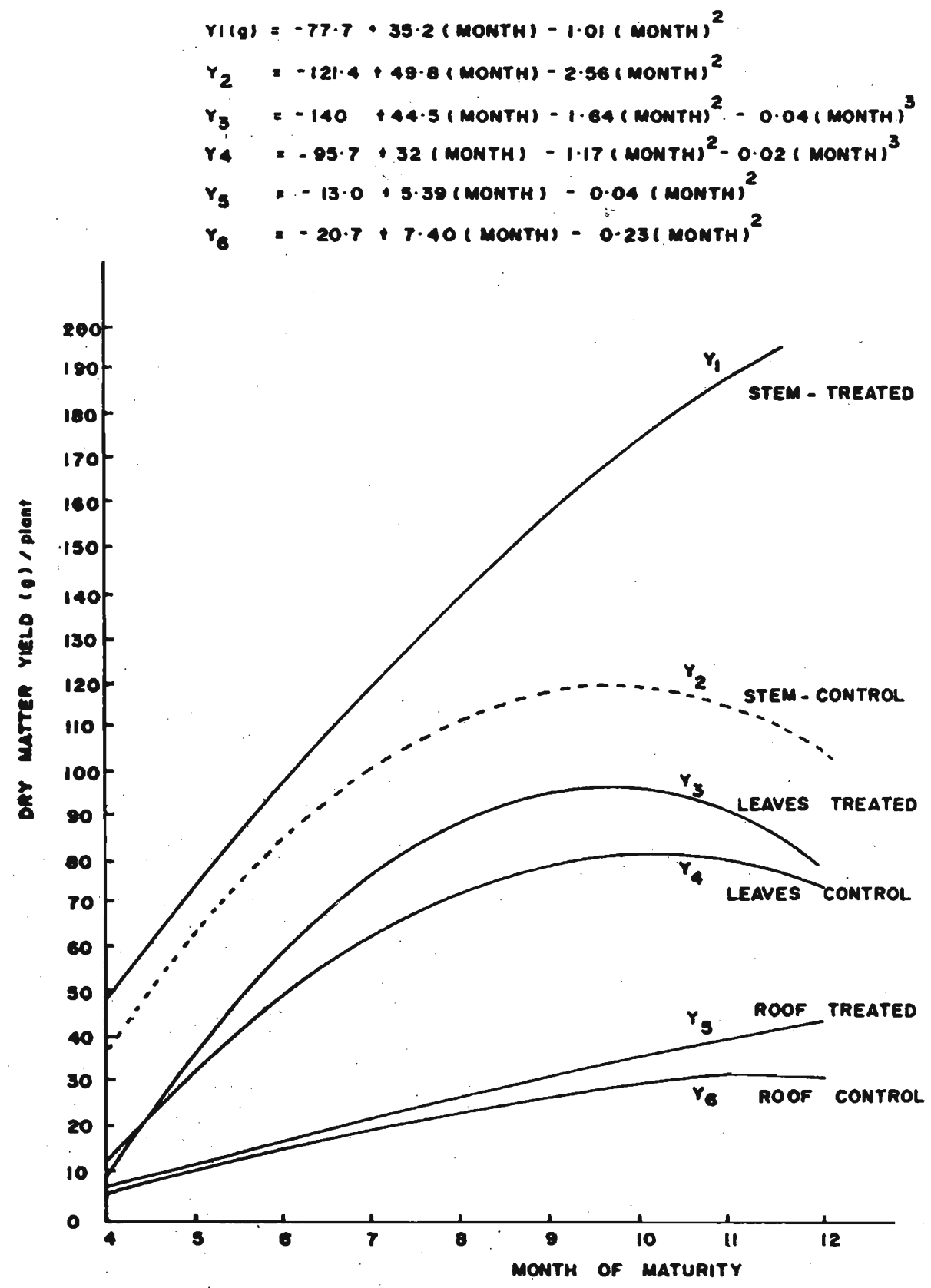

Figure 2. The variations in dry matter yield in $\mathrm{C}$. roseus 


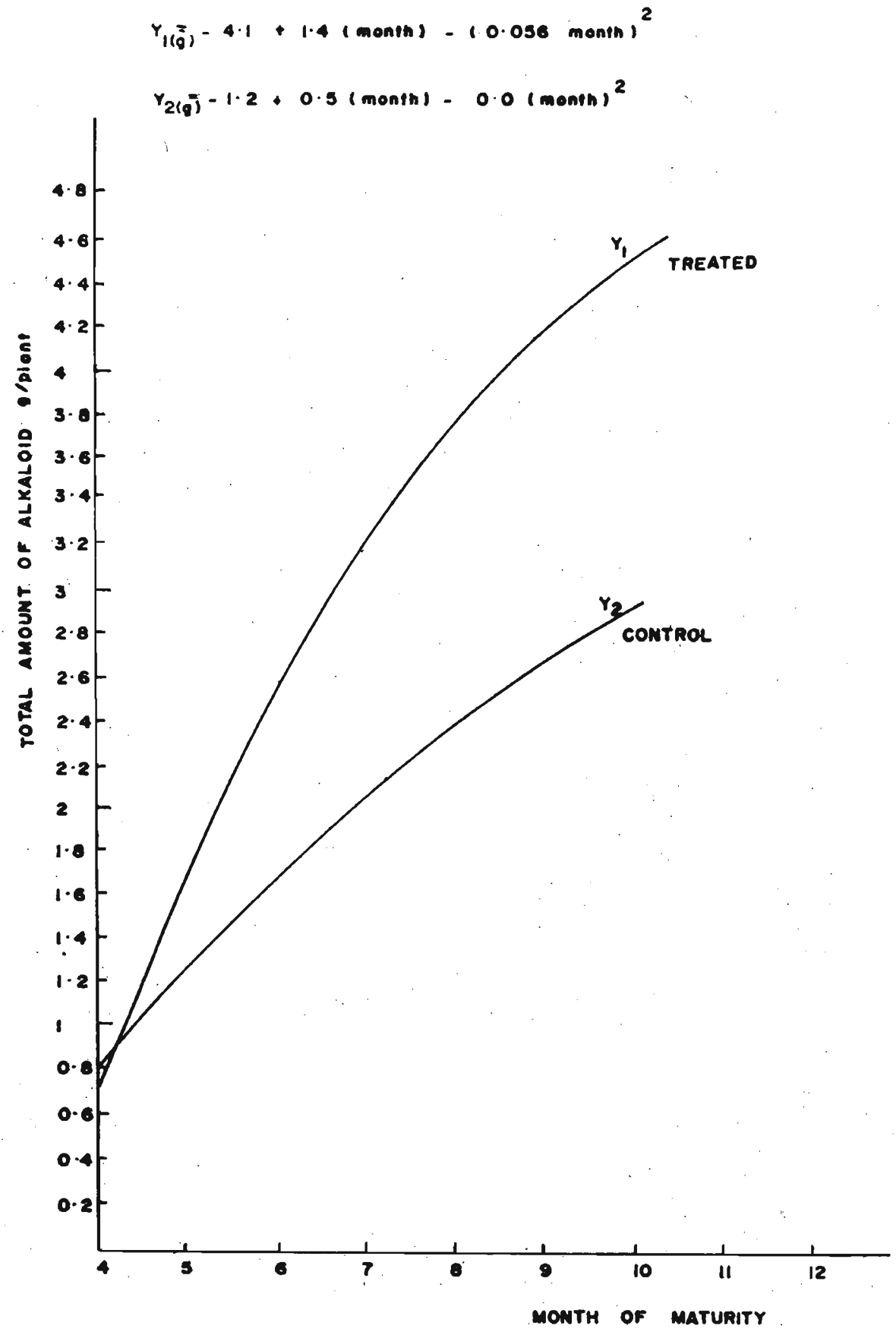

Figure 3: The changes in the yleld of alkaloids in C. roseus with follar application of plant nutrienta. 


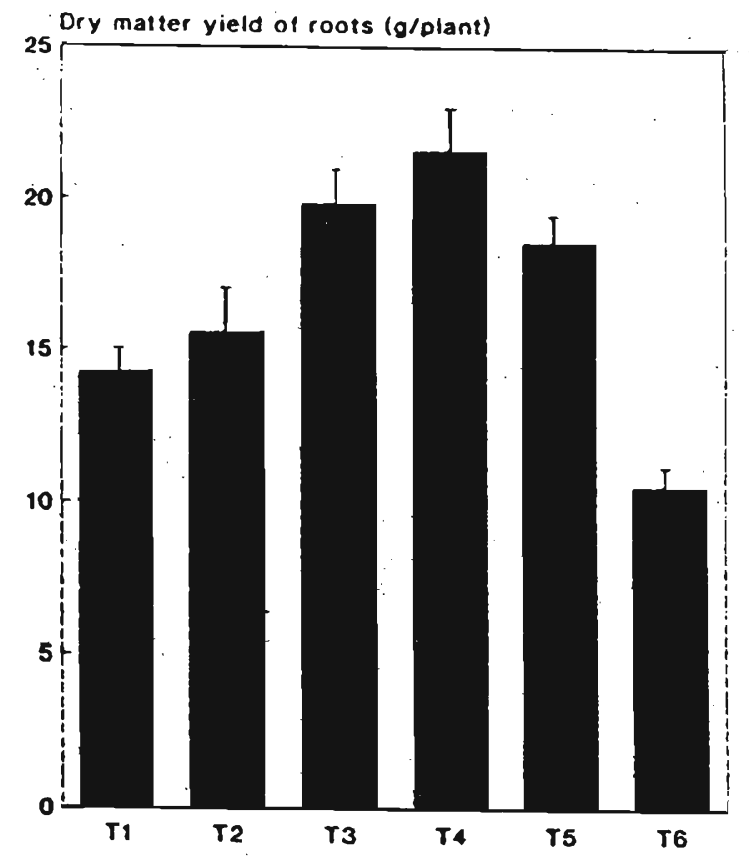

Figure 4: The effects of different treatments on the dry matter yleld of $C$. roseus at maturity. T1 without manure T2 - Catlle manure, T3 - N.P and K. T4 - N.P.K and nicro element, TS Cattle manure and micro elements mixture, T6 - Stress condition. Vertical bars indicate standard error of the mean.

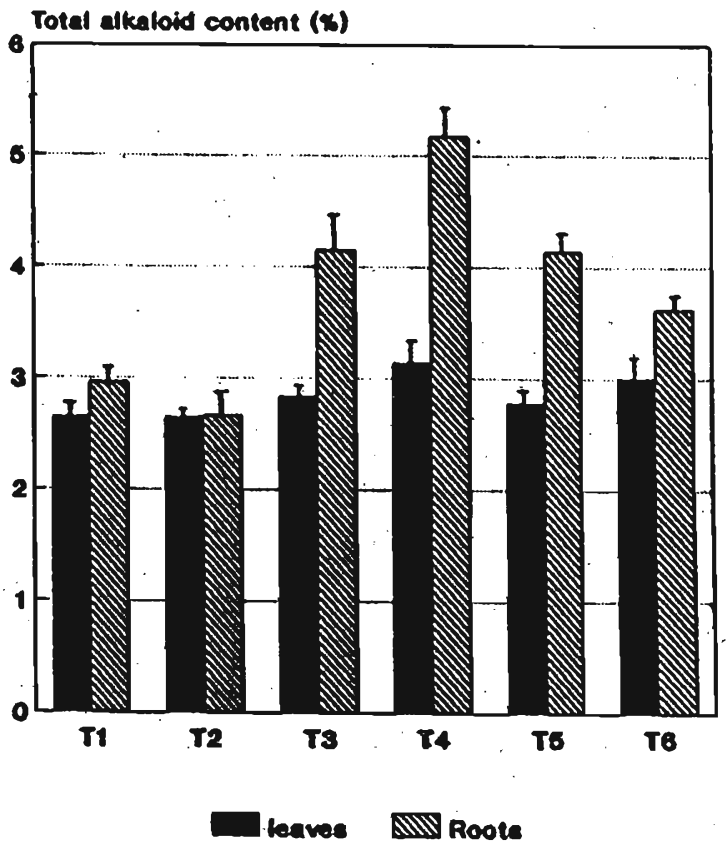

Figure 5: The effects of different treatments on the alkaloid contents of leaves and roots of $\mathrm{C}$. roseus at maturity T1 - without manure, T2 - Cattle manure, T3 - N.P and K, T4 - N.P.K and micro element, T5 - Cattle manure and micro element mixture, T6 - Stress condition. Vertical bars indicate standard error of the mean. 


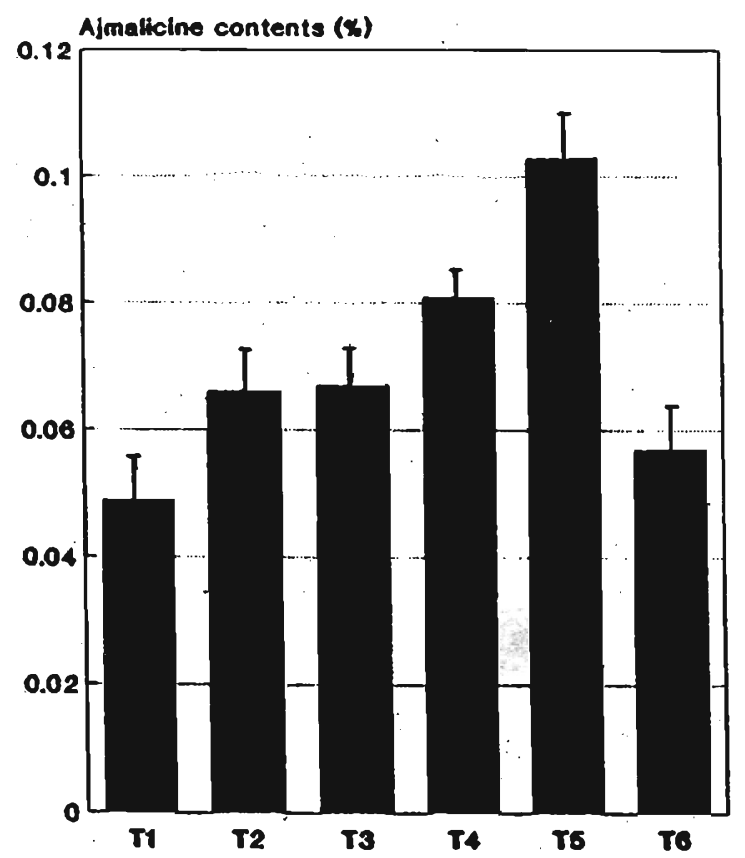

Figure 6: The effects of different treatments on the ajmalicine content of roots.

applied alone did not indicate any significant increase in the yields. The changes in the dry matter too followed a pattern similar to that of alkaloids. The stress conditions induced by pruning at the $3^{\text {rd }}$ month tended to increase total alkaloids compared to unprunned plants. Leaf stripping at the $3^{\text {rd }}$ month in addition to final harvest almost doubled the yield of leaves.

From these studies it can be concluded that the best time to harvest the plant is at the $10^{\text {th }}$ month of maturity. The maximum utilization of the land is then possible as sufficient time is available to prepare the land for the next cycle. The foliar application of plant nutrients and application of NPK - micro element mixture or NPK - cattle manure mixtures caused significant increases in the yields of dry matter and alkaloid contents. In addition these practices are economically feasible on a commercial scale.

\section{Acknowledgements}

The authors acknowledge research grants from the Ministry of Industries, Science and Technology, the International Foundation for Science, Sweden and the International Programme in Chemical Sciences, Uppsala, Sweden. 


\section{References}

1. Svoboda Q. H \& Blake A. (1975). Catharanthus alkaloids. In The Phytochemistry and Pharmacology (Eds. W. I. Taylor, N. Farnswoeth) pp. 45-81, New York.

2. Chatterjee S. K. (1980). Cultivation of medicinal plants in India with special reference to Eastern Himalayan regions. Proceedings of the $4^{\text {th }}$ Asian Symposium on medicinal plants and spices. pp. 20, Bangkok.

3. Ranatunga J., Arambewela L. S. R. \& Wijeratne W. (1985). Studies on the effects of fertilizer on the dry matter and alkaloid contents of Catharanthus roseus. Part 1. Proceedings of the SLAAS Annual Sessions pp. 103.

4. Ranatunga J., Arambewela L. S.R., Wijeratne S., Fernando P. \& Wickramasinghe C. K. (1986). Studies on the effects of fertilizer on the dry matter and alkaloid contents of Catharanthus roseus, Part II, Proceedings of the SLAAS Annual Sessions pp. 159. 